\title{
Klaus Wachtel: An Appreciation
}

Over almost three decades, Klaus Wachtel has made a peerless contribution to editorial work on the Greek New Testament. As a Research Fellow (Wissenschaftliche Mitarbeiter) at the Institut für neutestamentliche Textforschung (INTF) of the Westfälische Wilhelms-Universität in Münster, he has played a key role in a series of major publications which have significantly advanced our understanding of the text and transmission of the New Testament. From the completion of the volumes of Text und Textwert (the pioneering comparison of all known continuous-text manuscripts of the Greek New Testament), through the development and application of the Coherence-Based Genealogical Method (CBGM) in collaboration with its inventor, Gerd Mink, to the publication of new editions of the Nestle-Aland Novum Testamentum Graece and the successful completion of the first two installments of the landmark Novum Testamentum Graecum Editio Critica Maior (ECM), Klaus has been an integral and indispensable part of the team at the INTF. His mastery of and commitment to each stage of the editorial process, from proof-of-concept through to the final delivery of an edition, has led to the culmination of years of data collection and organisation in definitive editions which will serve scholarship for years to come.

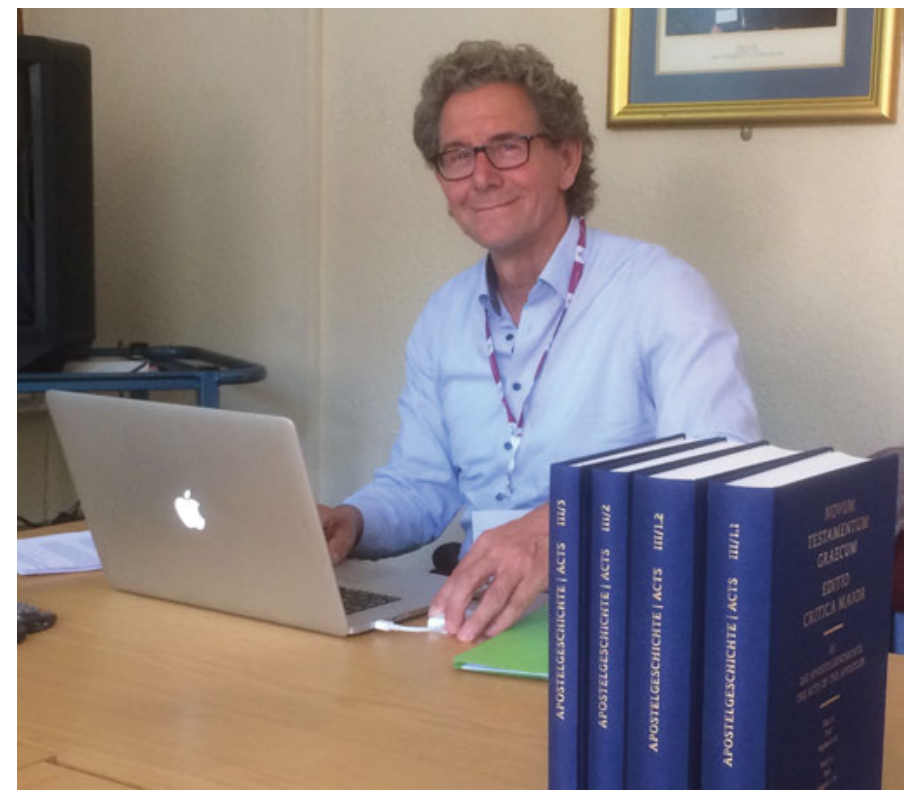


At the same time, Klaus's interest in digital technology has served to advance the production and integration of electronic tools to a degree which was inconceivable even thirty years ago. The way in which work on the Greek New Testament has been at the forefront of the development of software, the production and release of large quantities of data, and the creation of digital editions and resources which inspire confidence in their users, is due in large part to his effort and vision. Websites such as "New Testament Transcripts", the "New Testament Virtual Manuscript Room" (NT.VMR) and the online release of the apparatus of the ECM owe a huge deal to his patience and persistence. One of his oft-repeated lines, born of long experience, is that "with computers everything is quicker, but it takes longer.” Nevertheless, it is Klaus's example which has led to the embedding of the digital paradigm at the heart of New Testament textual criticism, working with huge amounts of data and pushing hardware, software and developers to their limits in order to cross the boundary to establish the new medium as a productive and valuable context for research.

Klaus's role as a leading co-worker in international research may be said to have begun in 1997, at the Society of Biblical Literature (SBL) Annual Meeting in San Francisco which saw the launch of the first fascicle of the ECM. As well as that important event, the weekend was marked by two other significant developments. The first was the attendance of Klaus, with Barbara Aland and Gerd Mink, at the annual meeting of the North American Committee of the International Greek New Testament Project (IGNTP). At this meeting Professor Aland took the initiative and proposed collaboration between the INTF and the IGNTP, so that the latter would be responsible for making the ECM of John. Over the years it has been Klaus who in many ways and places has made this partnership possible and has been instrumental in forging the relationships and ways of working which have been essential to the success of the collaboration. The second momentous event in San Francisco was that for the first time Peter Robinson presented his COLLATE program to an audience of biblical scholars. This led to a change in the methodology of both the ECM and the IGNTP. The foundation for editions became the electronic transcription rather than the collation, and COLLATE was adopted as the main tool for processing the Greek manuscript witnesses. Once again, it was Klaus who became the interface between the INTF, the new technology, and partners in the UK and elsewhere. And from that beginning in 1997 came the fresh ideas and detailed discussions that led to many of the most important tools available to us today, such as the NT.VMR and the tools for using the CBGM to analyse the relationships between witnesses.

The growth of scholarly collaboration fostered by the adoption of digital approaches to editing has not just been in the production of the ECM, now with a third major partner in Martin Karrer and his colleagues at the Institut für Septuaginta 
und Biblische Textforschung (ISBTF) in Wuppertal. Dozens of visiting researchers have benefitted from Klaus's time and expertise applied to their own projects. His partnership with Matthew Spencer and Christopher Howe at the University of Cambridge in the early 2000s, applying algorithms developed for evolutionary biology to New Testament textual traditions was truly groundbreaking. It seems that there is no-one for whom Klaus is unable to find time to discuss their work or assist with using the resources developed by the INTF, and his genuine interest and openness in the work of others is matched only by his desire that all research should realise its full potential. Most recently, Klaus has been involved in developing teams of New Testament researchers in Greece, a country particularly dear to him, in order to establish yet another generation and tradition of contribution to the task of editing the New Testament.

Klaus's impressive record of major collaborative publications is complemented by a series of individually-authored works. Best known is the major monograph on the Byzantine Text of the Catholic Epistles which arose from his doctorate at the INTF and earned him the sobriquet "Doktor Byz". This has been followed by a widely-cited piece on the development of the Byzantine Text of the Gospels. Klaus was one of the early voices to weigh in against Carsten Peter Thiede's redating of the Magdalen Papyrus, with a publication in the same journal as Thiede chose to set out his findings (the Zeitschrift für Papyrologie und Epigraphik). His accounts of the use of computers for the scholarly editing of the New Testament have enabled many to follow the direction of work at the INTF. More recently, Klaus has provided a number of chapters introducing and exemplifying the application of the CBGM. The collected volume of papers from the 2008 conference on the CBGM in Münster, co-edited with Michael W. Holmes as The Textual History of the Greek New Testament, including a major contribution by Gerd Mink, has also served the same purpose. His textual commentary accompanying the ECM of the Acts of the Apostles will be consulted by many, both online and in the printed volume.

To achieve so much requires patience and determination, openness and integrity. Every philologist has to have the first two characteristics. Fortunately, Klaus possesses the other two as well. His self-discipline, sitting down to edit at least one verse of the ECM each morning before attending to any other business, epitomises the single-mindedness which has enabled the delivery of the volumes of this edition which have so far been completed. At the same time, this is accompanied by a refreshing pragmatism. Suggestions for further developments, often born of the "feature creep" which besets many electronic projects, are met with the gentle reminder that "this is an Editio Maior, not an Editio Maxima." Collaborators seeking detailed guidance on the construction of a critical apparatus are simply given the principle that "variation units should be as short as possible and 
as long as necessary." Even the seemingly-endless array of presentations in which some adjustment or other is proposed to the apparatus of Nestle-Aland, however well-founded or not, are received with patience and courtesy. Klaus's commitment to the discipline and his collaborators is also seen in his regular attendance at conferences, where his participation in the social activities has also been a key element in promoting and developing cordial personal relationships with colleagues. Those who have participated in activities in Münster, especially during ECM editorial weeks, can also bear witness to his hospitality and friendship.

The number of people who could have participated in this volume is enormous, given the many scholars with whom Klaus has worked during his career. As editors, our gratitude goes to those who have contributed chapters, many of them deliberately focussed on aspects of New Testament transmission which the authors felt would be of particular interest to Klaus; all contributions, to a greater or lesser extent, are dependent on Klaus's own activities, which may be taken as a reflection of the breadth of his involvement in this field of research. There is also a handful of colleagues who wished to provide a chapter to honour Klaus but were prevented by force of circumstances. These include Amy Anderson, Simon Crisp, Eldon J. Epp, Christos Karakolis, Jennifer Knust, Curt Niccum, Ekaterini Tsalampouni, Beate von Tschischwitz and Dan Wallace. We would like to thank Albrecht Döhnert, Eva Frantz and their colleagues at De Gruyter for expediting the process of publication in order to ensure that it could be presented to Klaus during his final SBL meeting in post. As is customary for this series, abbreviations correspond to the SBL Handbook of Style.

Most important of all, we must express our thanks to Klaus for his collegiality, commitment and contribution to the discipline, and friendship. This volume is a small token of the appreciation and affection in which we hold him, and our gratitude for all our collaboration has brought over the last few decades.

H.A.G. Houghton, D.C. Parker, Holger Strutwolf Birmingham and Münster, Easter 2019. 